\section{OPEN ACCESS}

Edited by:

Mauro Fisberg

Federal University of São Paulo, Brazil

Reviewed by:

Emer Fitzpatrick,

King's College London

United Kingdom

Juan Francisco Rivera-Medina, Instituto Nacional de Salud del

Niño, Peru

*Correspondence:

Lorena Elena Melit

lory_chimista89@yahoo.com

Specialty section:

This article was submitted to

Pediatric Gastroenterology,

Hepatology and Nutrition,

a section of the journal

Frontiers in Pediatrics

Received: 26 January 2019

Accepted: 28 May 2019

Published: 18 June 2019

Citation:

Mărginean CO, Meliț LE, Ghiga DV and Mărginean MO (2019) Early Inflammatory Status Related to Pediatric Obesity.

Front. Pediatr. 7:241

doi: 10.3389/fped.2019.00241

\title{
Early Inflammatory Status Related to Pediatric Obesity
}

\section{Cristina Oana Mărginean ${ }^{1}$, Lorena Elena Meliț ${ }^{1 *}$, Dana Valentina Ghiga ${ }^{2}$ and Maria Oana Mărginean ${ }^{3}$}

1 Department of Pediatrics, University of Medicine, Pharmacy, Sciences, and Technology, Târgu Mureş, Romania, ${ }^{2}$ Department of Medical Informatics and Biostatistics, University of Medicine, Pharmacy, Sciences and Technology, Târgu Mureş, Romania, ${ }^{3}$ Department of Pediatric Cardiology, University of Medicine, Pharmacy, Sciences and Technology, Târgu Mureş, Romania

Background: Obese individuals are often in a chronic inflammatory condition due to the malfunction of immune-related activities in the adipose tissue, involving a transient infiltration of neutrophils within the abdominal fat and their binding to adipocytes. Neutrophil to lymphocyte ratio (NLR) and platelet to lymphocyte ratio (PLR) are considered cost-effective markers for the detection of subclinical inflammation. Our study intends to assess the early stages of inflammation associated with overweight and obesity in children.

Materials and Methods: We performed a prospective study with 164 children, aged between 5 and 18 years, admitted to a Pediatric Tertiary Hospital in Romania between January 2018 and January 2019. The patients were divided according to body mass index (BMI) into two groups: Group 1: 77 overweight and obese children (BMI percentile $\geq 85$ ), and Group 2: 87 children with a normal BMI, in order to evaluate the correlation between $\mathrm{BMI}$ and laboratory parameters (CBC, ESR, transaminase, total protein, albumin, and blood glucose levels), inflammatory biomarkers, NLR and PLR, and changes in abdominal ultrasound findings.

Results: We found that the leukocyte, lymphocyte, erythrocyte, platelet, CRP, and transaminase levels were significantly higher in the overweight/obese group $p=0.0379$, $p=0.0002, p=0.0003, p=0.0006, p<0.0001, p=0.0332$, and $p<0.0001$, respectively). No significant statistical differences between the two groups in terms of neutrophil, hemoglobin, albumin, total protein, and glycemia levels were noted ( $p>0.05$ ). Moreover, NLR and PLR did not differ significantly between the two groups ( $p=0.4674$ and $p=0.9973$, respectively).

Conclusions: Obesity is associated with systemic low-grade inflammation which is reaching alarming rates worldwide among both children and adults. Our study proved that leukocyte, lymphocyte, erythrocyte, and platelet levels are significantly higher in overweight/obese children, emphasizing the inflammatory status related to this condition. Therefore, obesity-related studies involving pediatric patients are of major interest in order to develop appropriate methods to prevent the development of further complications in adulthood.

Keywords: children, overweight, obese, neutrophil to lymphocyte ratio (NLR), platelet to lymphocyte ration (PLR) 


\section{INTRODUCTION}

Obesity is a current global health problem in both children and adults and causes a significant burden. Most studies investigating obesity involves adults; however, it is essential for studies to focus on childhood obesity in order to prevent its associated complications and further development in adulthood. The incidence of this nutritional disorder in children has reached alarming rates worldwide. In Romania, one in four children were found to be either overweight or obese (1). Its etiology is complex, involving an interaction between genetic susceptibility and environmental or "obesogenic" factors, which play a key role in triggering obesity, representing therefore the basis for successful interventions (2).

It is well-documented that obese individuals express a chronic inflammatory status; obesity-related complications, such as cardiovascular disease, type 2 diabetes mellitus, metabolic syndrome, and non-alcoholic steatohepatitis were proven to be results of obesity-associated low-grade inflammation $(3,4)$. This obesity-related inflammation is due to the malfunction of immune-related activities in the adipose tissue, involving a transient infiltration of neutrophils within the abdominal fat and their binding to adipocytes (5). This process may precede macrophage infiltration similar to that in other inflammatory conditions $(5,6)$. Moreover, neutrophils are the most important and abundant subtype of white blood cells in human peripheral blood. Neutrophils and chronic inflammation seem to be linked to chronic hypertension and obesity (7), with the total count of circulating neutrophils being increased in obese individuals (8). Besides neutrophils, leukocytes are also associated with obesityinduced chronic inflammatory status, being equally involved in related comorbidity development. Based on this premise, obese individuals without comorbidities are considered to represent a special subgroup in the early stage of inflammation similar to overweight individuals (9).

Multiple serum markers are said to be associated with low-grade chronic inflammation. Neutrophil to lymphocyte ratio (NLR) is a recently discovered, cost-effective marker for the detection of subclinical inflammation that correlates with C-reactive protein (CRP) levels (10-12). This useful marker has been related to multiple inflammatory conditions, cardiovascular diseases, and cancer $(13,14)$. NLR was shown to be directly related to the degree of inflammation (15). Platelet to lymphocyte ration (PLR) is another biomarker that can be calculated based on the complete blood count $(\mathrm{CBC})$ and has been proven to be useful in the diagnosis and monitoring of several systemic inflammatory processes (16-19). PLR is an indicator of the balance between inflammation and thrombosis. Thus, the inflammatory status results in accelerated megakaryocyte proliferation and associated thrombocytosis. Moreover, increased platelet counts and decreased lymphocyte counts have been shown to be related to both aggregation and

Abbreviations: ALT, alanine aminotransferase; AST, aspartate aminotransferase; BMI, body mass index; CBC, complete blood cellular; CRP, C-reactive protein; ESR, erythrocyte sedimentation rate; n, number; NLR, neutrophil/lymphocyte ratio; PLR, platelets/lymphocyte ratio; $\mathrm{SD}$, standard deviation. inflammation, and thus, represent risk indicators $(20,21)$. Other blood parameters, such as lymphocytes, monocytes, hemoglobin, erythrocyte sedimentation rate (ESR), total proteins, albumin, iron, cholesterol, triglycerides, and transaminases, and different gene polymorphisms, are related to childhood obesity and overweight (22-29).

The aim of this study was to assess different blood parameters associated with the low grade inflammatory status in overweight and obese children in order to detect the early stages of inflammation related to this nutritional disorder.

\section{MATERIALS AND METHODS}

\section{Study Sample}

We performed a prospective study with 191 pediatric patients aged between 5 and 18 years, referred to a Pediatric Tertiary Hospital in Romania, between January 2018 and January 2019 that were assessed on a 1 day admission chart system, without requiring long time hospitalization. However, the parents of only 173 children agreed to sign the informed consent form for their children to be included in the study. After selection according to age and sex, only 164 children were finally included in the study. The children were divided according the value of body mass index (BMI) into two groups: group 1, the study group: 77 overweight and obese children (overweight children: BMI percentile $\geq 85$ and $<95$, and obese children: BMI percentile $>95$ ), and group 2, the control group: 87 children with normal BMI (percentile $\geq 5$ and $<85$ ). The inclusion criteria for both groups was an age of between 5 and 18 years. In the study group we included children with a BMI percentile $>85$, while in the control group we included those with a BMI percentile $\geq 5$ and $<85$ (30-32). The exclusion criteria consisted of age below 5 years, secondary obesity, patients with obesity-related complications, chronic disorders, infectious diseases, incomplete data, and patients whose parents refused to sign the informed consent form.

All patients underwent a thorough anamnesis and clinical exam; blood parameters were also measured: CBC, ESR, CRP, transaminase, total protein, albumin, and blood glucose levels. Inflammatory biomarkers, such as NLR and PLR, were calculated by dividing the neutrophil count and platelet count, respectively, by the lymphocyte count. The abdominal ultrasound was performed in all children by a single trained clinician. The laboratory parameters were assessed using a Cobas Integra 400 plus automated analyzer, Roche Diagnostics GmbH, Mannheim, Germany. The ultrasound exams were performed with a probe, with variable frequencies between 2.5 and $6 \mathrm{MHz}$, and an $\mathrm{S} 8$ General Electric Machine.

All parents/caregivers signed the informed consent for their children. The study was approved by the Ethics Committee of the University of Medicine and Pharmacy of Târgu Mureș (No $329 /$ November 17th 2017), and it was performed according to the principles of the Helsinki Declaration.

\section{Statistical Analysis}

The children' characteristics are presented as means \pm standard deviation and medians. 
TABLE 1 | The descriptive analysis of the blood parameters in the two groups.

\begin{tabular}{|c|c|c|c|}
\hline Laboratory parameters & $\begin{array}{l}\text { Study group }(n=77) \\
\text { Mean } \pm \text { SD }\end{array}$ & $\begin{array}{l}\text { Control group }(n=87) \\
\text { Mean } \pm \text { SD }\end{array}$ & $p$-value \\
\hline Age (years) & $10.79 \pm 3.503$ & $12.33 \pm 3.516$ & ${ }^{*} 0.0052$ \\
\hline Birth weight (kg) & $3.310 \pm 0.5603$ & $3.278 \pm 1.070$ & ${ }^{*} 0.1400$ \\
\hline Current weight (kg) & $57.78 \pm 20.94$ & $45.36 \pm 14.46$ & $<0.0001$ \\
\hline Height (cm) & $146.8 \pm 17.83$ & $152.7 \pm 16.19$ & 0.0263 \\
\hline $\mathrm{BMI}\left(\mathrm{kg} / \mathrm{m}^{2}\right)$ & $25.82 \pm 4.518$ & $18.92 \pm 2.934$ & $<0.0001$ \\
\hline Leukocytes $\left(10^{3} / \mu l\right)$ & $7.932 \pm 2.885$ & $7.162 \pm 1.896$ & ${ }^{\star} 0.0379$ \\
\hline Neutrophils $\left(10^{3} / \mu \mathrm{l}\right)$ & $3.848 \pm 2293$ & $3.309 \pm 2210$ & ${ }^{*} 0.1063$ \\
\hline Lymphocytes $\left(10^{3} / \mu \mathrm{l}\right)$ & $2871 \pm 1042$ & $2382 \pm 743.3$ & ${ }^{\star} 0.0002$ \\
\hline Hemoglobin (g/dl) & $13.55 \pm 1.277$ & $13.45 \pm 1.193$ & ${ }^{*} 0.1776$ \\
\hline Erythrocytes (106/L) & $4.989 \pm 0.3986$ & $4.811 \pm 0.3863$ & $\star 0.0003$ \\
\hline Platelets $\left(10^{3} / \mu \mathrm{l}\right)$ & $338.0 \pm 100.3$ & $290.0 \pm 66.27$ & 0.0006 \\
\hline Albumin (g/dL) & $4.892 \pm 0.3255$ & $4.831 \pm 0.3290$ & 0.2295 \\
\hline Total proteins (g/dL) & $7.511 \pm 0.4958$ & $7.470 \pm 0.4247$ & 0.5676 \\
\hline AST (UI) & $26.87 \pm 23.78$ & $22.37 \pm 12.18$ & ${ }^{*} 0.0332$ \\
\hline ALT (UI) & $27.17 \pm 43.14$ & $14.68 \pm 9.655$ & ${ }^{*}<0.0001$ \\
\hline Glycaemia (mg/dl) & $86.33 \pm 9.527$ & $84.87 \pm 9.171$ & ${ }^{\star} 0.3338$ \\
\hline NLR & $1.577 \pm 0.8019$ & $1.878 \pm 1.527$ & ${ }^{*} 0.4673$ \\
\hline PLR & $125.9 \pm 44.77$ & $131.5 \pm 47.21$ & ${ }^{*} 0.9973$ \\
\hline ESR & $12.55 \pm 7.965$ & $11.32 \pm 8.690$ & *0.2122 \\
\hline CRP (mg/l) & $4.508 \pm 2.839$ & $1.938 \pm 4.729$ & ${ }^{*}<0.0001$ \\
\hline
\end{tabular}

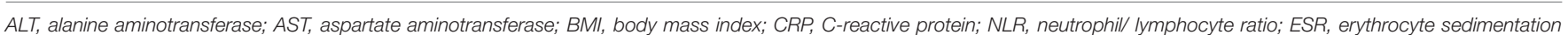
rate; $n$, number; PLR, platelets/lymphocyte ratio; $S D$, standard deviation; " Mann-Whitney test was used. $n=$ number. Bold represents the statistically significant values.

The statistical analysis comprised of descriptive statistical analysis (frequency, media, median, and standard deviations) and inferential statistical elements. D'Agostino \& Pearson's tests were applied in order to identify the distribution of the series of analyzed data. We applied the Student $t$-test for unpaired data, and the Mann-Whitney test for comparison of the medians. A Chi squared test was used for association determination. The significance threshold was considered at a $p$-value of 0.05 . The statistical analysis was performed using GraphPad Prism 7 free trial version, GraphPad Software Inc., California, USA.

\section{RESULTS}

Among the 164 children included in the study, the mean age for the study group was $10.79 \pm 3.503$ years, whereas that for the control group was $12.33 \pm 3.516$ years $(p=0.0052)$. Regarding residence area, we found the same distribution of obese children among rural and urban areas $(p=0.8338)$, without a significance influence of the social status in the development of obesity. According to sex distribution, being overweight/obese was more common in boys $(p=0.0083)$. Thus, our sample is age- and sex-matched. We also assessed the birth weight, identifying a higher value for control group, $3.278 \pm 1.070 \mathrm{~kg}$ in comparison to $3.310 \pm 0.5603 \mathrm{~kg}$ for obese children, but without statistical significance $(p=0.1400)$. The current weight and BMI of the children included in our study were significantly higher for obese group $(p<0.0001)$. Thus, the mean value of the current weight was $57.78 \pm 20.94 \mathrm{~kg}$ for obese children versus $45.36 \pm 14.46 \mathrm{~kg}$ for control group, while the mean value of
BMI in case of obese children was of $25.82 \pm 4.518 \mathrm{~kg} / \mathrm{m}^{2}$ compared to $18.92 \pm 2.934 \mathrm{~kg} / \mathrm{m}^{2}$ for normal weight children. Contrariwise, the height was higher for control group, though without statistical significance $(p=0.0263)$, with a mean value of $152.7 \pm 16.19 \mathrm{~cm}$ for control group in comparison to 146.8 $\pm 17.83 \mathrm{~cm}$ for obese children. All these descriptive parameters along with the values of the laboratory parameters are mentioned in Table 1.

Among the blood parameters, we found that leukocyte (Figure 1), lymphocyte (Figure 2), erythrocyte, platelet (Figure 3), CRP (Figure 4), and transaminase levels (AST and ALT) were significantly higher in the overweight/obese children in contrast to the control group $(p=0.0379, p=$ $0.0002, p=0.0003, p=0.0006, p<0.0001, p=0.0332$, and $p<$ 0.0001 , respectively).

Nevertheless, we did not encounter any significant statistical differences between the two groups in terms of neutrophil, hemoglobin, albumin, total protein, erythrocyte sedimentation rate (ESR), and glycemia levels ( $p=0.1063, p=0.1776, p=$ $0.2295, p=0.5676, p=0.2122$, and $p=0.3338$, respectively). Moreover, NLR and PLR did not differ significantly between the two groups ( $p=0.4674$ and $p=0.9973$, respectively).

Regarding the results of the abdominal ultrasound, we found pathological changes, such as hepatomegaly and hepatic steatosis, in $77.92 \%$ of the overweight/obese children, whereas, in the control group, only three children were identified to have hepatomegaly (3.44\%). Thus, hepatomegaly and hepatic steatosis were significantly more frequent in the overweight/obese group than in the normal BMI group ( $p>0.0001)$ (Table 2). 

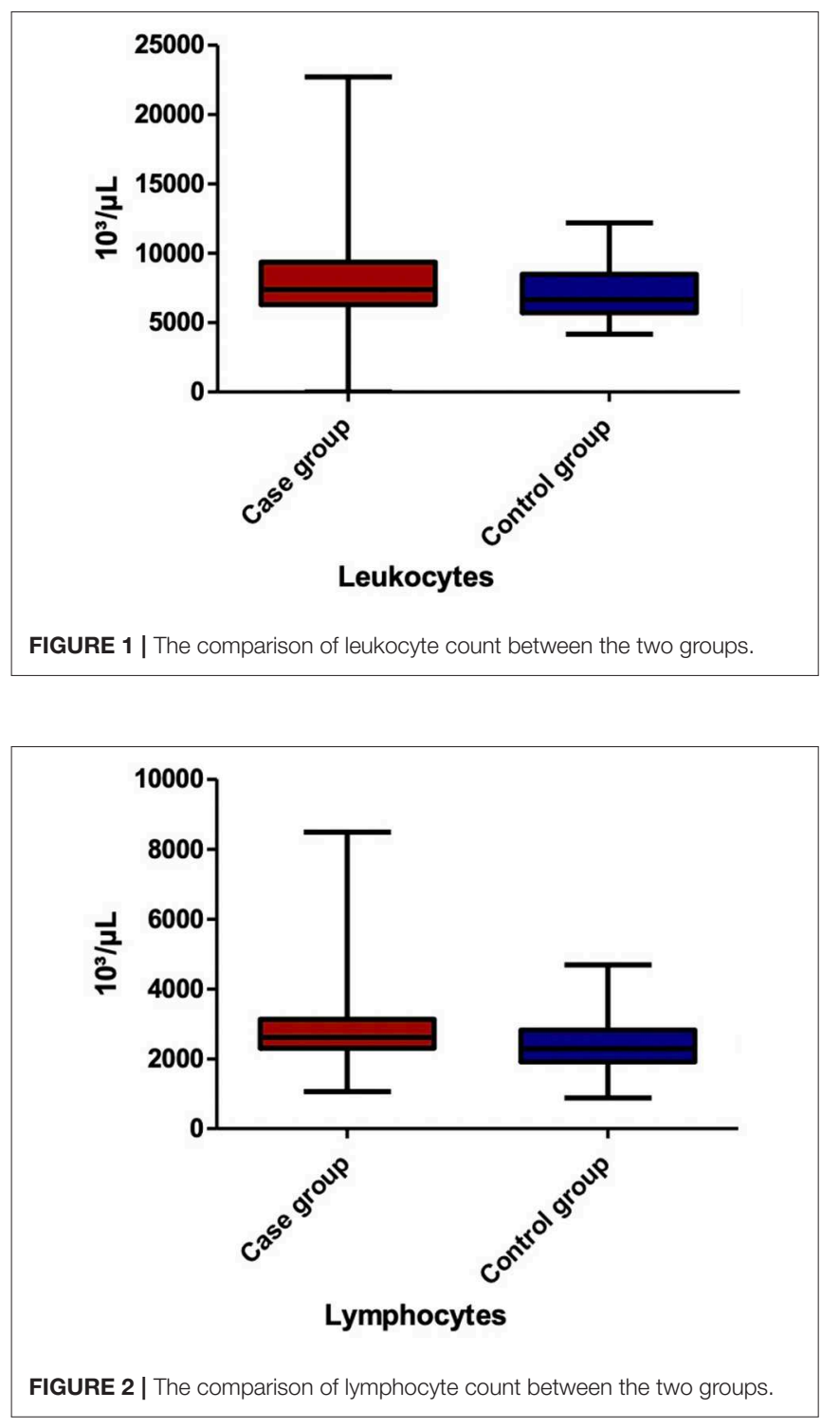

\section{DISCUSSIONS}

The World Health Organization stated that the prevalence of obesity worldwide has nearly tripled since 1975 (33). Thus, in 2016, 41 million children below the age of 5 years were overweight or obese (33). The prevalence of obesity increases with age, with over 340 million children and adolescents aged between 5 and 19 years being affected with this condition in 2016 (33). Obesity is an important leading cause of mortality worldwide, being associated with increased risk for heart failure, stroke, skeletal system diseases, and malignancies (33).

The adipose tissue has been proven to contribute to both the initiation and maintenance of systemic inflammation $(5,34)$. Adipose tissue-related inflammation leads to a wide variety of immune responses, involving neutrophil participation in the early phases followed by macrophage involvement and mast cell polarization $(35,36)$. Studies performed on mice proved that
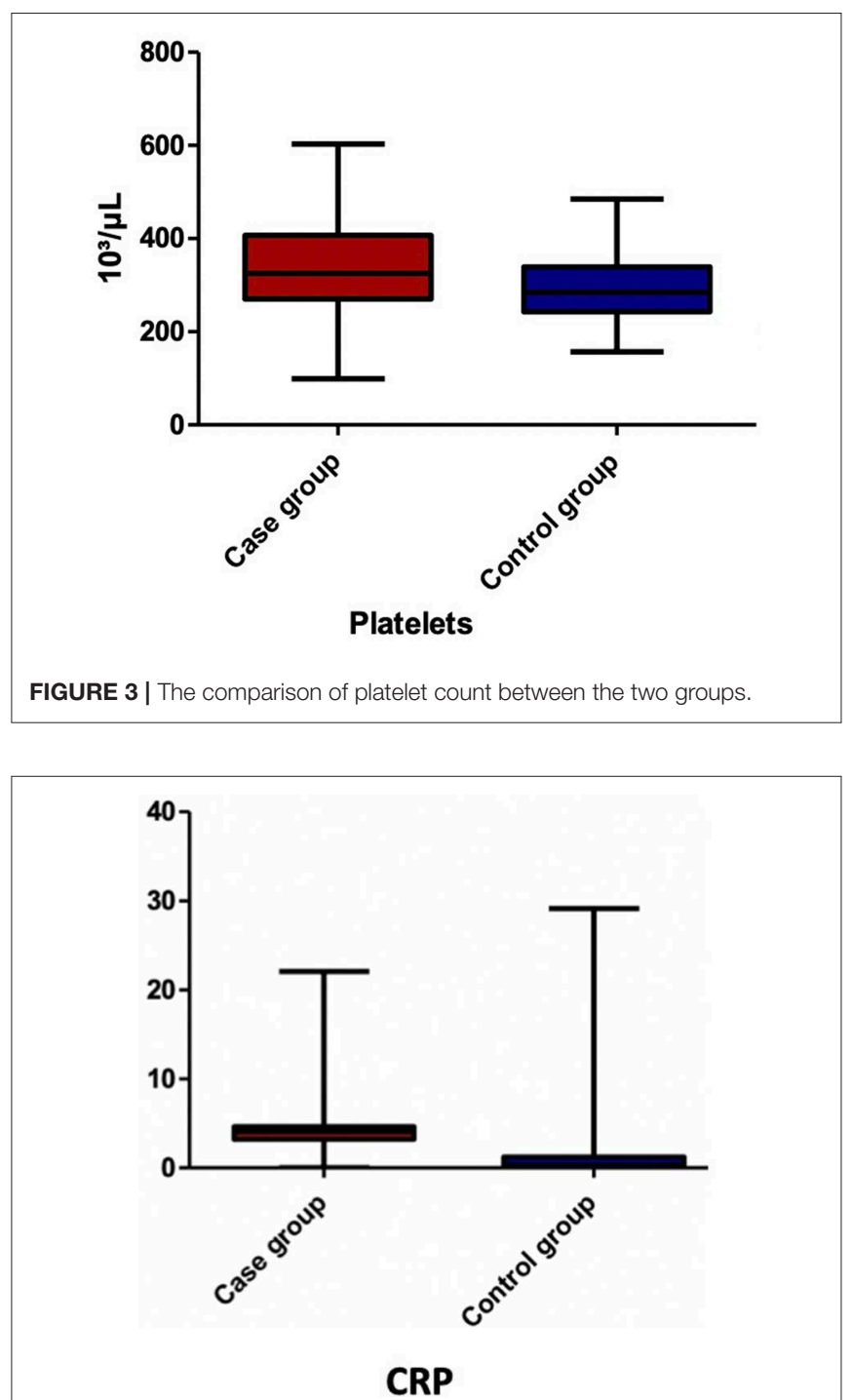

FIGURE 4 | The comparison of CRP value between the two groups.

the neutrophil count significantly increases within the adipose tissue even in the first days after the initiation of a high fat diet (37), suggesting that obesity, even in its early stages, is associated with systemic inflammation. Similar findings were also reported in humans in the study of Tam et al. (38), who underlined that acute lipid overload is related to the increase of inflammatory biomarkers, such as CRP and monocyte chemoattractant protein-1. Our study sustains the findings of Tam et al. regarding the CRP, which was significantly higher in the obese/overweight children included in this research. Recently, a wide range of biomarkers were found to be related to low-grade systemic inflammations, such as CBC parameters, NLR, PLR, mean platelet volume, and CRP among others. Thus, it was proven that the peripheral blood of otherwise healthy overweight/obese individuals exhibit characteristics of a low-grade inflammation (6). 
TABLE 2 | Comparative analysis of liver ultrasound findings between the two groups.

\begin{tabular}{lcc}
\hline $\begin{array}{l}\text { Abdominal } \\
\text { ultrasound }\end{array}$ & $\begin{array}{c}\text { Study group } \\
\text { (77 cases) }\end{array}$ & $\begin{array}{c}\text { Control group } \\
\text { (87 cases) }\end{array}$ \\
\hline Hepatomegaly & 13 & 3 \\
Normal & 17 & 84 \\
Steatosis & 19 & 0 \\
Hepatomegaly, & 27 & 0 \\
steatosis & 1 & 0 \\
Steatohepatitis & & \\
areas & & \\
surrounding & & \\
the gallbladder & & \\
\hline
\end{tabular}

White blood cells were shown to be associated with the development of metabolic syndrome $(39,40)$. A study performed with 6,700 patients found positive correlations between waist circumference and leukocyte, lymphocyte, neutrophil, and platelet levels, and medium platelet volume (41). Moreover, another study including 223 subjects showed that an increase in BMI results in increased leukocyte, lymphocyte, platelet, and neutrophil counts (42). Similar to the findings of the previously mentioned study, our study showed a significant correlation between being overweight/obese and leukocyte, platelet, lymphocyte, and erythrocyte counts. However, it failed to show a significant association of these conditions with the neutrophil count. Despite the fact that NLR and PLR are immune response markers related to chronic inflammation $(19,43)$, we did not find significant correlations between these markers and obesity/overweight. The lack of correlation between NLR and BMI in our study might be explained by the significant increase in lymphocyte count among overweight/obese children. Most likely, PLR did not correlate with an increased BMI in our study due to the significant increase in both platelet and lymphocyte counts in the overweight/obese group. Recent studies emphasize the role of NLR as a potential inflammation marker in not only cardiac and non-cardiac disorders, but also autoimmune conditions and infections $(44,45)$. Inflammatory status is reflected by neutrophil counts, while the lymphocyte count is linked to the nutritional status and general stress (46). The increase in neutrophil count was proven to be directly related to the degree of obesity (47). Thus, the fact that in our study we did not find a significant increase in neutrophil count among the study group might be explained by the young age of our subjects, resulting in an insufficient amount of time for chronic inflammation to occur. Moreover, multiple studies have focused on assessing the role of NLR and PLR in patients with related-comorbidities; a study performed with 155 obese and non-obese patients with obstructive sleep apnea found significantly higher values in terms of NLR among obese individuals (46). Metabolic syndrome related obesity is another disorder commonly associated with chronic inflammation that was found to be related with NLR (48). Nevertheless, the findings remain contradictory because similar to our study, Bahadir et al. also failed to prove an association between NLR and obesity or metabolic syndrome (49). Diabetes mellitus and its related metabolic malfunctions are also associated with an increased NLR (50).

Most obesity-related studies have been performed using adult participants and stated that the wide range of associated comorbidities hinder the elucidation of a cause-effect link between inflammation and obesity (51). Similar to our study, Aydin et al. performed a study with 187 children (130 obese individuals and 57 healthy controls) (51). They found that the age of obese children was lower than that of the healthy controls in their study. Regarding blood parameters, the authors showed that lymphocyte and neutrophil counts, and NLR were significantly higher in obese children. Similarly, our study also showed a significant increase in lymphocyte count among overweight/obese children, but it failed to show significant differences in terms of neutrophil count and NLR between the normal BMI children and those with high BMI. Moreover, the previously mentioned study (51) did not identify any significant differences between obese and normal weight children with respect to PLR, as in our study. These contradictory findings might be explained by the fact that pediatric cases are rarely accompanied by obesityrelated complications.

The limitations of our study consist of the relatively small sample size and the lack of correlation with dietary habits and the assessment of related complications. Conversely, this study will make a significant contribution to the existing literature as it involved pediatric patients and was able to identify the risk factors associated with the early phases of obesity-related inflammatory process. Moreover, to the best of our knowledge, this is the first study in Romania that assessed the role of CBC parameters, NLR, and PLR in overweight/obese children.

\section{CONCLUSIONS}

Obesity is associated with systemic low-grade inflammation and is reaching alarming rates worldwide among both children and adults. Our study proved that leukocyte, lymphocyte, erythrocyte, and platelet counts are significantly higher in overweight/obese children, emphasizing the early inflammatory status related to this condition. Therefore, obesity-related studies involving pediatric patients are crucial in order to develop appropriate methods for preventing the development of further complications in adulthood.

\section{ETHICS STATEMENT}

The study was approved by the Ethics Committee of the University of Medicine and Pharmacy of Târgu Mureş (No 329/ November 17th 2017), and it was performed according to the principles of the Helsinki Declaration. The consent procedure used in our study consisted in an informed written consent that was signed by all parents/caregivers for their children prior to 
the inclusion in the study. The study was also explained to the children signed and we obtained their verbal assent.

\section{AUTHOR CONTRIBUTIONS}

CM, LM, and MM conceptualized and designed the study, drafted the initial manuscript, and reviewed, and revised the manuscript. MM and LM designed the data collection instruments, collected data, carried out the initial analyses, and reviewed and revised the manuscript. DG performed the

\section{REFERENCES}

1. Chirita-Emandi A, Barbu CG, Cinteza EE, Chesaru BI, Gafencu M, Mocanu V, et al. Overweight and underweight prevalence trends in children from Romania-pooled analysis of cross-sectional studies between 2006 and 2015. Obes Facts. (2016) 9:206-20. doi: 10.1159/0004 44173

2. Mărginean $\mathrm{CO}$, Mărginean $\mathrm{C}$, Melit LE. New insights regarding genetic aspects of childhood obesity: a mini review. Front Pediatr. (2018) 6:271. doi: 10.3389/fped.2018.00271

3. Tilg $\mathrm{H}$, Moschen AR. Adipocytokines: mediators linking adipose tissue, inflammation and immunity. Nat Rev Immunol. (2006) 6:772-83. doi: $10.1038 /$ nri1937

4. Ferrante AW. Obesity-induced inflammation: a metabolic dialogue in the language of inflammation. J Intern Med. (2007) 262:408-14. doi: 10.1111/j.1365-2796.2007.01852.x

5. Elgazar-Carmon V, Rudich A, Hadad N, Levy R. Neutrophils transiently infiltrate intra-abdominal fat early in the course of high-fat feeding. J Lipid Res. (2008) 49:1894-903. doi: 10.1194/jlr.M800132-JLR200

6. Trellakis S, Rydleuskaya A, Fischer C, Canbay A, Tagay S, Scherag A, et al. Low adiponectin, high levels of apoptosis and increased peripheral blood neutrophil activity in healthy obese subjects. Obes Facts. (2012) 5:305-18. doi: $10.1159 / 000339452$

7. Shah TJ, Leik CE, Walsh SW. Neutrophil infiltration and systemic vascular inflammation in obese women. Reprod Sci. (2010) 17:116-24. doi: $10.1177 / 1933719109348252$

8. Dixon JB, O'Brien PE. Obesity and the white blood cell count: changes with sustained weight loss. Obes Surg. (2006) 16:251-7. doi: 10.1381/096089206776116453

9. Vargas R, Ryder E, Diez-Ewald M, Mosquera J, Durán A, Valero N, et al. Increased C-reactive protein and decreased Interleukin-2 content in serum from obese individuals with or without insulin resistance: associations with leukocyte count and insulin and adiponectin content. Diabetes Metab Syndr. (2016) 10 (1 Suppl. 1):S34-41. doi: 10.1016/j.dsx.2015. 09.007

10. Keskin Kurt R, Okyay AG, Hakverdi AU, Gungoren A, Dolapcioglu KS, Karateke A, et al. The effect of obesity on inflammatory markers in patients with PCOS: a BMI-matched case-control study. Arch Gynecol Obstet. (2014) 290:315-9. doi: 10.1007/s00404-014-3199-3

11. Celikbilek M, Dogan S, Ozbakir O, Zararsiz G, Kücük H, Gürsoy S, et al. Neutrophil-lymphocyte ratio as a predictor of disease severity in ulcerative colitis. J Clin Lab Anal. (2013) 27:72-6. doi: 10.1002/jcla.21564

12. Imtiaz F, Rashed MS, Al-Mubarak B, Allam R, El-Karaksy H, Al-Hassnan $\mathrm{Z}$, et al. Identification of mutations causing hereditary tyrosinemia type I in patients of Middle Eastern origin. Mol Genet Metab. (2011) 104:688-90. doi: 10.1016/j.ymgme.2011.06.019

13. Ataseven A, Bilgin AU, Kurtipek GS. The importance of neutrophil lymphocyte ratio in patients with psoriasis. Mater Sociomed. (2014) 26:231-3. doi: $10.5455 / \mathrm{msm} .2014 .231-233$

14. Templeton AJ, McNamara MG, Šeruga B, Vera-Badillo FE, Aneja P, Ocaña A, et al. Prognostic role of neutrophil-to-lymphocyte ratio in solid tumors: a systematic review and meta-analysis. J Natl Cancer Inst. (2014) 106:dju124. doi: $10.1093 /$ jnci/dju124 statistical analysis. All authors approved the final manuscript as submitted and agree to be accountable for all aspects of the work.

\section{FUNDING}

This research was partially supported by the UEFISCDI grant: The development of an innovative diagnostic guide of obese child through genetics, anthropometric, bioimpedance, and ultrasound assessment, project number: 8159/27.07.2017-PNIII-P4-ID-PCE-2016-0766.
15. Imtiaz F, Shafique K, Mirza SS, Ayoob Z, Vart P, Rao S. Neutrophil lymphocyte ratio as a measure of systemic inflammation in prevalent chronic diseases in Asian population. Int Arch Med. (2012) 5:2. doi: 10.1186/1755-7682-5-2

16. Saşkin H, Düzyol Ç, Özcan KS, Aksoy R, Idiz M. Preoperative platelet to lymphocyte ratio is associated with early morbidity and mortality after coronary artery bypass grafting. Heart Surg Forum. (2015) 18:E255-62. doi: 10.1532/hsf.1341

17. Tagawa T, Anraku M, Morodomi Y, Takenaka T, Okamoto T, Takenoyama $\mathrm{M}$, et al. Clinical role of a new prognostic score using plateletto-lymphocyte ratio in patients with malignant pleural mesothelioma undergoing extrapleural pneumonectomy. J Thorac Dis. (2015) 7:1898-906. doi: 10.3978/j.issn.2072-1439.2015.11.15

18. Emir S, Aydin M, Can G, Bali I, Yildirim O, Öznur M, et al. Comparison of colorectal neoplastic polyps and adenocarcinoma with regard to NLR and PLR. Eur Rev Med Pharmacol Sci. (2015) 19:3613-8.

19. Sahin F, Yildiz P. Serum platelet, MPV, PCT and PDW values, neutrophil to lymphocyte and platelet to lymphocyte ratios in lung cancer diagnosis. Eur Respir J. (2015) 46 (Suppl. 59):PA4279. doi: 10.1183/13993003.congress-2015.PA4279

20. Çakiroglu Y, Vural F, Vural B. The inflammatory markers in polycystic ovary syndrome: association with obesity and IVF outcomes. J Endocrinol Invest. (2016) 39:899-907. doi: 10.1007/s40618-016-0446-4

21. Balta S, Ozturk C. The platelet-lymphocyte ratio: a simple, inexpensive and rapid prognostic marker for cardiovascular events. Platelets. (2015) 26:680-1. doi: 10.3109/09537104.2014.979340

22. Mărginean C, Mărginean CO, Bănescu C, Melit L, Tripon F, Iancu M. Impact of demographic, genetic, and bioimpedance factors on gestational weight gain and birth weight in a Romanian population: a cross-sectional study in mothers and their newborns: the Monebo study (STROBE-compliant article). Medicine. (2016) 95:e4098. doi: 10.1097/MD.0000000000004098

23. Mărginean C, Mărginean CO, Iancu M, Szabo B, Cucerea M, Melit LE, et al. The role of TGF- $\beta 1869 \mathrm{~T}>\mathrm{C}$ and PPAR $\gamma 234 \mathrm{C}>\mathrm{G}$ polymorphisms, fat mass, and anthropometric characteristics in predicting childhood obesity at birth: a cross-sectional study according the parental characteristics and newborn's risk for child obesity (the newborns obesity's risk) NOR study. Medicine. (2016) 95:e4265. doi: 10.1097/MD.0000000000004265

24. Mărginean CO, Bănescu C, Duicu C, Voidăzan S, Mărginean C. Angiotensin-converting enzyme gene insertion/deletion polymorphism in nutritional disorders in children. Eur J Nutr. (2015) 54:1245-54. doi: 10.1007/s00394-014-0802-0

25. Mărginean CO, Mărginean C, Voidăzan S, Melit L, Crauciuc A, Duicu $\mathrm{C}$, et al. Correlations between leptin gene polymorphisms $223 \mathrm{~A} / \mathrm{G}$, 1019 G/A, 492 G/C, 976 C/A, and anthropometrical and biochemical parameters in children with obesity: a prospective case-control study in a romanian population-the nutrichild study. Medicine. (2016) 95:e3115. doi: 10.1097/MD.0000000000003115

26. Mârginean C, Mărginean C, Iancu M, Moldovan V, Melit L, Bănescu C. The impact of TNF- $\alpha 308 \mathrm{G}>\mathrm{A}$ gene polymorphism in child's overweight risk coupled with the assessment of biochemical parameters - a crosssectional single center experience. Pediatr Neonatol. (2018) 60:19-27. doi: 10.1016/j.pedneo.2018.03.003

27. Mărginean C, Bănescu CV, Mărginean CO, Tripon F, Melit LE, Iancu M. Glutathione S-transferase (GSTM1, GSTT1) gene polymorphisms, maternal 
gestational weight gain, bioimpedance factors and their relationship with birth weight: a cross-sectional study in Romanian mothers and their newborns. Rom J Morphol Embryol. (2017) 58:1285-93.

28. Oana MC, Claudia B, Carmen D, Maria PA, Septimiu V, Claudiu M. The role of IL-6 572 C/G, 190 C/T, and 174 G/C gene polymorphisms in children's obesity. Eur J Pediatr. (2014) 173:1285-96. doi: 10.1007/s00431-014-2315-5

29. Mărginean C, Mărginean CO, Iancu M, Melit LE, Tripon F, Bănescu C. The FTO rs9939609 and LEPR rs1137101 mothers-newborns gene polymorphisms and maternal fat mass index effects on anthropometric characteristics in newborns: a cross-sectional study on mothers-newborns gene polymorphisms-The FTO-LEPR Study (STROBE-compliant article). Medicine. (2016) 95:e5551. doi: 10.1097/MD.0000000000005551

30. Krebs NF, Himes JH, Jacobson D, Nicklas TA, Guilday P, Styne D. Assessment of child and adolescent overweight and obesity. Pediatrics. (2007) 120 (Suppl. 4):S193-228. doi: 10.1542/peds.2007-2329D

31. Mantzouranis N, Pilianidis T, Douda H, Tokmakidis S. Comparison of international obesity taskforce cutoffs, centers for disease control and prevention growth charts, and body mass index Z-score values in the prevalence of childhood obesity: the Greek obesity and lifestyle study. Pediatrics. (2008) 121(Suppl. 2):S149. doi: 10.1542/peds.2007-2022 GGGGGG

32. Defining Childhood Obesity $\mid$ Overweight \& Obesity $\mid$ CDC. Available online at: https://www.cdc.gov/obesity/childhood/defining.html (accessed January 20, 2019).

33. WHO|Overweight and Obesity. Available online at: https://www.who.int/gho/ ncd/risk_factors/overweight/en/ (accessed January 25, 2019).

34. Pecht T, Gutman-Tirosh A, Bashan N, Rudich A. Peripheral blood leucocyte subclasses as potential biomarkers of adipose tissue inflammation and obesity subphenotypes in humans. Obes Rev. (2014) 15:322-37. doi: 10.1111 /obr.12133

35. Lolmède K, Duffaut C, Zakaroff-Girard A, Bouloumié A. Immune cells in adipose tissue: key players in metabolic disorders. Diabetes Metab. (2011) 37:283-90. doi: 10.1016/j.diabet.2011.03.002

36. Chatzigeorgiou A, Karalis KP, Bornstein SR, Chavakis T. Lymphocytes in obesity-related adipose tissue inflammation. Diabetologia. (2012) 55:2583-92. doi: 10.1007/s00125-012-2607-0

37. Talukdar S, Oh DY, Bandyopadhyay G, Li D, Xu J, McNelis J, et al. Neutrophils mediate insulin resistance in mice fed a high-fat diet through secreted elastase. Nat Med. (2012) 18:1407-12. doi: 10.1038/nm.2885

38. Tam CS, Viardot A, Clément K, Tordjman J, Tonks K, Greenfield JR, et al. Short-term overfeeding may induce peripheral insulin resistance without altering subcutaneous adipose tissue macrophages in humans. Diabetes. (2010) 59:2164-70. doi: 10.2337/db10-0162

39. Fadini GP, Marcuzzo G, Marescotti MC, de Kreutzenberg SV, Avogaro A. Elevated white blood cell count is associated with prevalence and development of the metabolic syndrome and its components in the general population. Acta Diabetol. (2012) 49:445-51. doi: 10.1007/s00592-012-0402-5

40. Jung CH, Lee WY, Kim BY, Park SE, Rhee EJ, Park CY, et al. The risk of metabolic syndrome according to the white blood cell count in apparently healthy Korean adults. Yonsei Med J. (2013) 54:615-20. doi: 10.3349/ymj.2013.54.3.615

41. Vuong J, Qiu Y, La M, Clarke G, Swinkels DW, Cembrowski G. Reference intervals of complete blood count constituents are highly correlated to waist circumference: should obese patients have their own "normal values?" Am J Hematol. (2014) 89:671-7. doi: 10.1002/ajh.23713

42. Furuncuoglu Y, Tulgar S, Dogan AN, Cakar S, Tulgar YK, Cakiroglu B. How obesity affects the neutrophil/lymphocyte and platelet/lymphocyte ratio, systemic immune-inflammatory index and platelet indices: a retrospective study. Eur Rev Med Pharmacol Sci. (2016) 20:1300-6.

43. Hong X, Cui B, Wang M, Yang Z, Wang L, Xu Q. Systemic immuneinflammation index, based on platelet counts and neutrophil-lymphocyte ratio, is useful for predicting prognosis in small cell lung cancer. Tohoku J Exp Med. (2015) 236:297-304. doi: 10.1620/tjem.236.297

44. Dogan M, Akyel A, Bilgin M, Erat M, Çimen T, Sunman H, et al. Can admission neutrophil to lymphocyte ratio predict infarct-related artery patency in ST-segment elevation myocardial infarction. Clin Appl Thromb Hemost. (2015) 21:172-6. doi: 10.1177/1076029613515071

45. Ozbay I, Kahraman C, Balikci HH, Kucur C, Kahraman NK, Ozkaya DP, et al. Neutrophil-to-lymphocyte ratio in patients with peripheral vertigo: a prospective controlled clinical study. Am J Otolaryngol. (2014) 35:699-702. doi: 10.1016/j.amjoto.2014.08.004

46. Bozkuş F, Dikmen N, Samur A, Bilal N, Atilla N, Arpag H. Does the neutrophil-to-lymphocyte ratio have any importance between subjects with obstructive sleep apnea syndrome with obesity and without obesity? Tuberk Toraks. (2018) 66:8-15. doi: 10.5578/tt.66535

47. Atmaca H, Akbaş F, Ökten I, Nuhoglu E, Belçik Inal B. Can neutrophil-tolymphocyte ratio serve as an inflammatory marker in obesity? Istanbul Med J. (2014) 15:216-20. doi: 10.5152/imj.2014.75046

48. Syauqy A, Hsu CY, Rau HH, Chao JC. Association of dietary patterns, anthropometric measurements, and metabolic parameters with C-reactive protein and neutrophil-to-lymphocyte ratio in middle-aged and older adults with metabolic syndrome in Taiwan: a cross-sectional study. Nutr J. (2018) 17:106. doi: 10.1186/s12937-018-0417-Z

49. Bahadir A, Baltaci D, Türker Y, Türker Y, Iliev D, Öztürk S, et al. Is the neutrophil-to-lymphocyte ratio indicative of inflammatory state in patients with obesity and metabolic syndrome? Anatol J Cardiol. (2015) 15:816-22. doi: 10.5152/akd.2014.5787

50. Lee CT, Harris SB, Retnakaran R, Gerstein HC, Perkins BA, Zinman B, et al. White blood cell subtypes, insulin resistance and $\beta$-cell dysfunction in highrisk individuals-the PROMISE cohort. Clin Endocrinol. (2014) 81:536-541. doi: $10.1111 /$ cen. 12390

51. Aydin M, Yilmaz A, Donma MM, Tulubas F, Demirkol M, Erdogan M, et al. Neutrophil/lymphocyte ratio in obese adolescents. North Clin Istanb. (2015) 2:87-91. doi: $10.14744 /$ nci.2015.25238

Conflict of Interest Statement: The authors declare that the research was conducted in the absence of any commercial or financial relationships that could be construed as a potential conflict of interest.

Copyright (c) 2019 Mărginean, Meliţ, Ghiga and Mărginean. This is an open-access article distributed under the terms of the Creative Commons Attribution License (CC $B Y)$. The use, distribution or reproduction in other forums is permitted, provided the original author(s) and the copyright owner(s) are credited and that the original publication in this journal is cited, in accordance with accepted academic practice. No use, distribution or reproduction is permitted which does not comply with these terms. 